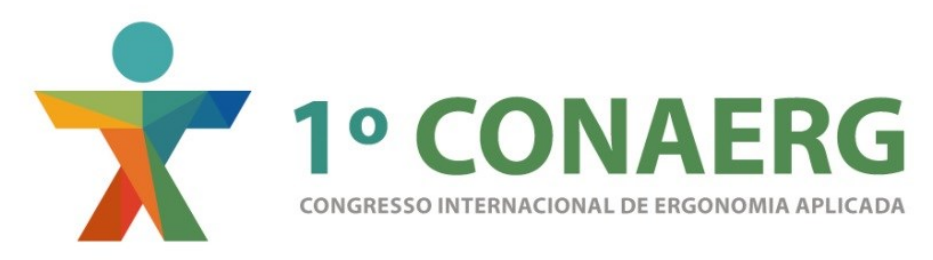

\title{
VALIDAÇÃO PROJETUAL: TESTE PRELIMINAR DE USABILIDADE EM UM PROTÓTIPO DE UM HANDBIKE
}

\author{
Raimundo Diniz (1); \\ Larissa Ferro (2) \\ (1) Programa de Pós-Graduação em Design, Núcleo de Ergonomia em Processos e Produtos \\ (UFMA), Doutor em Engenharia de Produção \\ e-mail: rl.diniz@ufma.br \\ (2) Núcleo de Ergonomia em Processos e Produtos (UFMA), Bolsista PIBIC (CNPq), \\ Graduanda em Design. \\ e-mail: larahferro@gmail.com
}

\begin{abstract}
RESUMO
O presente artigo visa apresentar uma proposta de validação preliminar em um protótipo de handbike. O teste foi ponderado na avaliação a partir do seu comparativo com a literatura técnica. Como complemento, realizou-se um teste preliminar (pré-teste) envolvendo a situação real de uso por parte de usuários em potencial, considerando pessoas com deficiência e sem deficiência, com experiência e sem experiência. No geral, observou-se que há a necessidade de alguns ajustes quanto ao design, como por exemplo: dimensionamento antropométrico, biomecânica da empunhadura do guidão e possibilidade de alternância de posturas quando do acionamento do guidão para o seu deslocamento. Destaca-se, ainda, o fato de que os testes preliminares apontaram para uma percepção positiva em relação ao seu uso, com níveis de satisfação elevados por parte dos sujeitos participantes, principalmente dos usuários com deficiência.
\end{abstract}

\begin{abstract}
This article aims to present a proposal for preliminary validation of a handbike prototype. The test was weighted in the evaluation from your comparison to references. Also, there was a preliminary test (pre-test) involving the actual situation of use by potential users, considering people with disabilities and without disabilities, experienced and inexperienced. In general, it was observed that there is need for some adjustments on the design, such as: anthropometrics, grip and, the possibility of posture when the handlebar trigger for its displacement. In fact, preliminary tests indicated a positive perception of their use, with high levels of satisfaction on the part of the participating subjects, especially users with disabilities.
\end{abstract}

\section{INTRODUÇÃO}

Assim como uma das atribuições da Ergonomia é equiparar oportunidades a indivíduos com diferentes potencialidades e limitações através da adequação de processos, produtos e ambientes, é atribuição da acessibilidade integral, segundo Bins Ely et. Al. (2002), o uso com segurança e conforto de objetos, equipamentos e ambientes de maneira independente e autônoma pelo maior número possível de 
indivíduos. Logo, acessibilidade pressupõe conhecer as limitações dos indivíduos para projetar ambientes livres de barreiras arquitetônicas e de informação, buscando a integração pessoas sem deficiência e pessoas com deficiência, sem distinção.

Em Novembro de 2011, o IBGE divulgou os primeiros resultados do Censo Demográfico de 2010 relativos aos temas pesquisados no inquérito da amostra no que tange, entre outros, a deficiência. No referido senso, os resultados preliminares apontam que 45 milhões de brasileiros estão acometidos a algum tipo de deficiência. Cria-se assim, a necessidade de reintegrar as pessoas com deficiência à sociedade $e$ suas atividades diárias, a partir do desenvolvimento de novos produtos e ajudas técnicas, como a handbike, uma vez que pode contribuir com a qualidade de vida das pessoas com deficiência, auxiliando-as na sua locomoção e transporte.

Contudo, para o desenvolvimento destes produtos é indispensável a aplicação da ergonomia, essencialmente a ergonomia da reabilitação que, segundo Nowak (1999), proporciona o bem estar físico e mental do deficiente, melhorando seu desempenho motor e sua postura, consequentemente, aumentando sua qualidade de vida e contribuindo para o não surgimento de problemas físicos (posturais), mentais e psíquicos, interagindo o deficiente no seu ambiente físico e de trabalho, respeitando suas capacidades, habilidades e limitações. Desta forma, para a melhoria das condições de usabilidade, a proposta de projeto de produto denominada "Handbike" a qual pode ser categorizada como um tipo ou classe de handbike - realizou-se um teste de usabilidade preliminar durante o uso da referida proposta, com objetivo de propor a geração de subsídios que pudessem aprimorar a projetação ergonômica do projeto "Handbike", tendo como premissa a aplicação da acessibilidade em relação às suas atividades diárias, dos seus usuários, como o lazer, o trabalho e 0 condicionamento físico.

\section{PROJETO HANDBIKE}

As handbikes são, geralmente, triciclos (figura 1), nos quais o sistema mecânico de acionamento para o movimento das rodas são manivelas. Usam, também, os mesmos sistemas de câmbio, freios e penus das bicicletas (The manual wheelchair training guide, 1998). O usuário da handbike realiza tanto o trabalho dinâmico (ao girar os dispositivos para a sua impulsão utilizando os membros superiores); quanto ao trabalho estático (na manutenção, durante longos períodos, da posição sentada). Em determinadas situações, a forma de manejo utilizada é o grosseiro (empunhadura), como é o caso dos movimentos mais velozes e com menor precisão no acionamento (sistema de manivelas), assim como o manejo fino (pega), envolvendo maior precisão de movimento e menos aplicação de força (sistema de câmbio).

Figura 01 - Tipo de Handbike

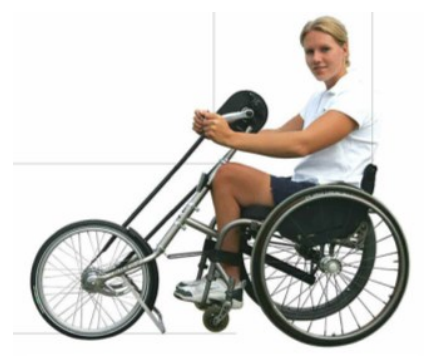

Fonte: Mobiliteit or Maat, (s.d.)

É possível afirmar que as handbikes são integralmente "extensões" do corpo do usuário. Extensão possibilitada a partir de dispositivos (controles) que serão ativados pelo seu trabalho físico muscular, para a movimentação e transporte. Os controles 
usados na handbike são manivelas ("pedal") e alavancas (freio e sistema de câmbio). Partindo-se desta descrição, pode-se apontar que o projeto em questão apresenta características muito próximas, similares, ao handbike, havendo diferença no sistema de acionamento, uma vez que este é realizado por um sistema mecânico movido por uma alavanca (guidom) a qual aciona uma catraca, tracionando assim, a roda (pneu) direita e, então, ocasionando a sua movimentação (figura 2).

Figura 02. Sistema de acionamento mecânico da Parabike

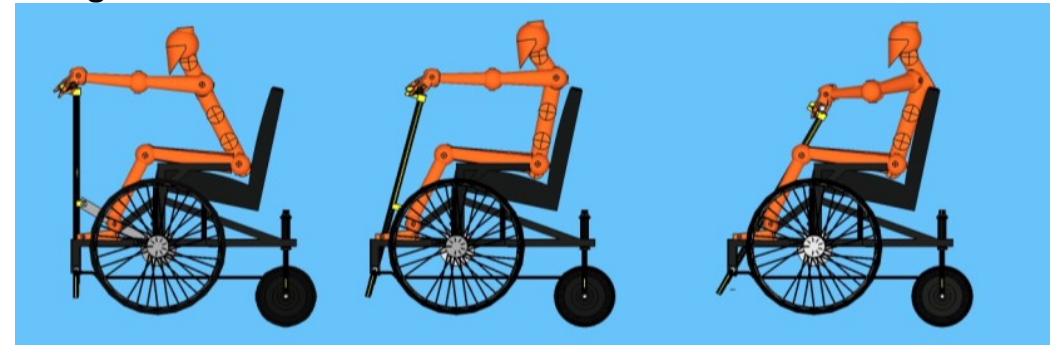

Fonte: Elaborada pelos autores.

Batista (2005) realizou uma pesquisa envolvendo o uso de "handbikes não industriais" (figura 03), projetadas e fabricadas de maneira empírica, exclusivas e de forma artesanal. Em síntese, os questionários aplicados por Batista (2005) apontaram diversos constrangimentos ergonômicos que lhe permitiram elaborar requisitos projetuais para a projetação de handbikes.

Figura 3. Exemplos de posturas adotadas com o uso de handbikes artesanais

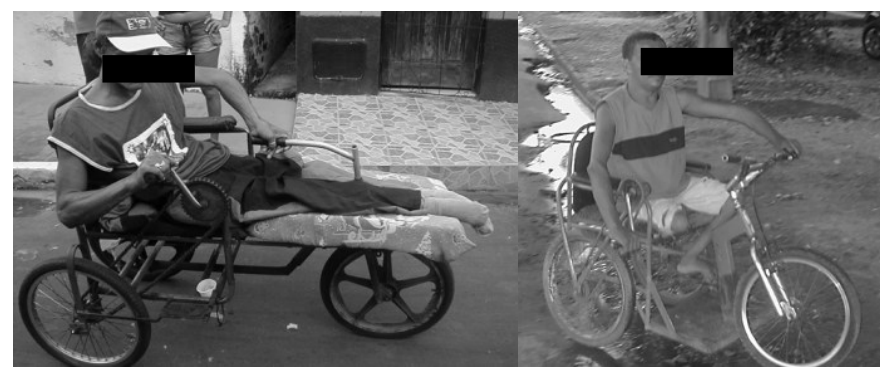

Fonte: Retirada de Batista (2005).

Além dos requisitos, os resultados dos testes realizados por Batista (2005), permitiram a elaboração de uma proposta (figura 04) que teve por objetivo, servir de instrumento para testes de usabilidade e incentivar novas discussões sobre futuros projetos de handbikes e similares.

Figura 4. Proposta preliminar de handbike

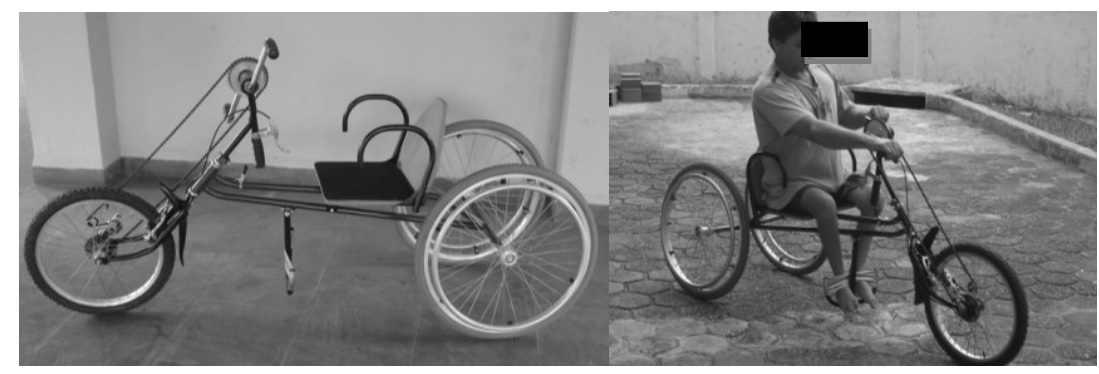

Fonte: Retirada de Batista (2005)

A partir de seus resultados, Batista (2005) recomenda requisitos projetuais para a projetação de handbikes, dentre eles: Produto para transporte de pessoas, passeio, trabalho e condicionamento físico; Produto que substitui o andar (marcha humana) para transporte de pessoas (extensão do corpo humano); Não soltar peças e 
respingos de resíduos no corpo do usuário, ser estável (não tombar); Não possuir peças com pontas, cantos vivos expostos; Proteção dos "dentes" das catracas e coroas; Fácil manutenção e reposição de peças sendo o mesmo das bicicletas e/ou cadeiras de roda convencionais; Soldas, encaixe e acabamentos de fácil manutenção; Fácil limpeza; Fácil manuseio no giro, engrenagens e direcionamento do sistema de manivelas; Sistema de freios simples similar ao das bicicletas convencionais; Sistema de marchas (câmbio) similar ao das bicicletas convencionais; Assento confortável para longo tempo de uso; Encosto no formato triangular ou trapezoidal para evitar desconforto nos braços ao manipular as manivelas; Apoio para braços (em intervalos, paradas,etc.); Apoio para as pernas; Sistema de manivela e câmbio para manejo grosseiro; Baixo nível de ruído resultante dos sistemas mecânicos; Baixo nível de vibração entre os sistemas mecânicos; Não acumular resíduos; Dimensionamento antropométrico adequado; Ser usado em praias, sítios, chácaras sem o perigo de atolar ou derrapar; Fácil desmontagem para ser guardado em veículos pequenos urbanos; Dimensões compatíveis para acesso a coletivos (ônibus, van, etc.).

\section{MÉTODOS E TÉCNICAS}

Considera-se a presente avaliação como de cunho descritivo, de caráter exploratório, pois visa obter informações sobre a realidade da análise de uma hanbike em situação de uso, bem como a possibilidade de implementar melhorias. A abordagem descritiva envolve quatro aspectos: a descrição, o registro, a análise e a interpretação de fenômenos (Marconi \& Lakatos, 1996). O caráter exploratório tem por objetivo proporcionar maior familiaridade com o problema, com vistas a torná-lo mais explícito ou a construir hipóteses. Para a avaliação do projeto realizaram-se os seguintes procedimentos (parâmetros) avaliativos: A) Observações Sistemáticas: por meio de registro fotográfico e em vídeo, além de anotações em caderneta de campo, durante o uso da handbike, seguindo os resultados apontados pela Análise da Tarefa. Os resultados das observações sistemáticas serviram de base para a elaboração de um questionário fechado (de validação). $O$ objetivo foi realizar uma descrição quanto ao uso prescrito da handbike, destacando-se também eventuais constrangimentos ergonômicos. A referida descrição foi modelada conforme o fluxograma sequencia das funções/operações/atividades (modelagem sistêmica) (Moraes \& Mont'Alvão, 1998); B) Questionário fechado: detectar o nível de percepção dos sujeitos (usuários da handbike) quanto aos fatores relativos à sua usabilidade. Cada questão foi aferida por meio de uma escala de avaliação contínua (Stone et al., 1974), com duas âncoras nas extremidades (incompreensível e compreensível) e uma âncora no centro (neutro), com $15 \mathrm{~cm}$ de comprimento, e ao longo dela o sujeito (respondente) deve marcar a sua percepção sobre o item. O questionário não requereu o nome dos respondentes, mas requereu dados pessoais (idade, sexo, profissão, peso, altura, etc.). Para a tabulação, considerou-se o peso de cada item gerando-se a média aritmética entre as respostas dos respondentes; C) Mapa de Regiões Corporais (MRC): avaliar a percepção do desconforto/dor incidente sobre os segmentos corporais onde, subjetivamente, os respondentes marcam numa escala de avaliação o nível de desconforto/dor de acordo com a subdivisão dos segmentos corporais existentes numa figura humana pré-elaborada (CORLETT, 1995). A versão utilizada apresentou uma escala contínua de $8 \mathrm{~cm}$ com âncoras referentes ao nível de desconforto/dor $(0=$ nenhum; 8 = muito). O MRC foi aplicado quando do uso simulado do "Parabike" em um intervalo de tempo pré-estipulado, conforme os resultados da análise da tarefa. Os pontos (valores) foram transcritos para uma planilha Excel para que fossem analisadas de acordo com a sua média aritmética; D) Checagem de fatores inerentes às normas $e$ recomendações técnico-científicas: uso dos dados da pesquisa realizada por (NBR9050:2004), BATISTA (2005), DREYFUSS (2005), PANERO \& ZELNIK (2002), RAMOS (2004) e NETO-SILVA (2007) como parâmetro de verificação dos principais 
atributos relativos à usabilidade e, ainda, os critérios utilizados na NBR-9050:2004. Para tal, realizou-se, também, um levantamento técnico dimensional, por meio de uma trena de precisão e paquímetro, buscando-se uma comparação do seu dimensionamento com a literatura disponível; E) Cinemetria (avaliação do esforço físico): foi utilizada uma câmera filmadora Panasonic NV-VZ175BR localizada a 3 metros de distância, no plano sagital dos sujeitos. Foram utilizados marcadores esféricos, confeccionados com EVA e tinta fluorescente, fixados sobre a pele dos sujeitos nas articulações: ombro (acrômio), cotovelo (epicôndilo lateral), ulna (processo estilóide). Os dados foram analisados por meio do software MaxTRAQ ${ }^{\circledR}$ (Innovision Systems, 2006), verificando-se a variação angular do cotovelo e do ombro para identificar as fases que compõem a locomoção do usuário, tendo-se como referência KROEMER (1999) (figura 3).

Figura 5. Variação angular do cotovelo versus a força (em Newtons) exercida em pessoas sentadas em movimentos de empurrar e puxar.

\begin{tabular}{c|cc|cc}
\multirow{2}{*}{$(1)$} & \multicolumn{2}{|c|}{$\langle 2)$} & \multicolumn{2}{c}{ (3) } \\
\hline $\begin{array}{c}\text { Degree of elbow } \\
\text { flexation (deg) }\end{array}$ & Pull & \multicolumn{2}{|c}{ Push } \\
\cline { 2 - 5 } & Left Right & $\mathrm{L}$ & $\mathrm{R}$ \\
\hline 180 & 222 & 231 & 187 & 222 \\
150 & 187 & 249 & 133 & 187 \\
120 & 151 & 187 & 116 & 160 \\
90 & 142 & 165 & $\frac{98}{96}$ & 160 \\
60 & 116 & 107 & 96 & 151
\end{tabular}

F) Freqüência Cardíaca (FC) (avaliação do esforço físico): foi utilizado um monitor de FC da marca POLAR ${ }^{\circledR}$ modelo S610. Os dados foram registrados pelo monitor a cada 5 segundos durante o uso da handbike, em tarefas diferentes (uso em uma via horizontal, trajeto reto, em superfície plana e uso em uma via horizontal, trajeto reto e curvilíneo, em superfície plana). Antes de iniciar o teste, foi mensurada a FC em repouso. Foi expresso o esforço físico (carga de trabalho) conforme Apud (1997): FCmédia inferior a 75bpm = esforço muito leve; FCmédia entre 76 e $100 \mathrm{bpm}=$ esforço medianamente pesado; FCmédia entre 101 e 125 = esforço pesado e FCmédia entre 126 e 150bpm = esforço extremamente pesado. Para o cálculo da FCMáxima utilizaram-se as seguinte fórmulas: $\mathrm{FCM}=198-(0,42 \times$ idade $)$, para indivíduos treinados (experientes), e FCM $=205-(0,42 \times$ idade), para indivíduos destreinados (inexperientes) (Sheffield et al., 1965). Os dados foram transferidos para o software Polar Precision Performance ${ }^{\mathrm{TM}}$, por meio de uma interface com sistema infravermelho, tabulados e plotados em gráfico, a cada 5 segundos.

\subsection{Sujeitos participantes (definição da amostra)}

Utilizou-se uma amostragem aleatória não-probabilística estratificada (MARCONI e LAKATOS, 1996), sendo a listagem da população inicial subdividida em subconjuntos (estratos), retirando-se de cada um, amostras aleatórias simples (MOURA et al.,1998). Os estratos foram baseados em atributos dos indivíduos como sexo, idade, peso, altura, frequência de atividade física, destreza manual e Percentil antropométrico, levando-se em consideração o percentíl menor do sexo feminino (P5M) e o percentíl maior do sexo masculino $(\mathrm{P} 95 \mathrm{H})$, para se ter um quadro comparativo entre os usuários extremos. Para tal, adotou-se a tabela antropométrica para a variável estatura de Panero \& Zelnik (2002). O critério de seleção dos indivíduos aconteceu mediante a disponibilidade e interesse voluntário em participar do teste. Na presente pesquisa, contou-se com a participação de 02 (dois) voluntários de percentis P95H e P5M, sendo pessoas sem deficiência e inexperientes (grupo A). Em um segundo momento, houve a participação de 02 (dois) voluntários com deficiência, praticantes de atividade física regular (grupo B) e experientes. Todos os participantes tiveram sua identidade 
preservada e foram informados a respeito do objetivo da pesquisa assinando um Termo de Consentimento Livre e Esclarecido. Os sujeitos foram instruídos a respeito da utilização da Handbike, quanto às posições e movimentos adequados a serem adotados e, ainda, pelos pesquisadores a respeito dos procedimentos e protocolos relativos ao teste.

\section{RESULTADOS E DISCUSSÕES}

\subsection{Observações Sistemáticas}

A handbike possui um fluxo operacional simples e de fácil entendimento. De maneira geral, há três principais atividades: 1 . Acesso ao assento; 2 . Manuseio do guidão e; 3. Saída do assento. Ressalta-se que, para as atividades 1 e 2 há a necessidade de se posicionar o guidão no ângulo de 90 graus, na tentativa de ter maior espaço para as manobras de entrada e saída da Handbike (figura 6).

Figura 6. Registro fotográfico das observações sistemáticas.

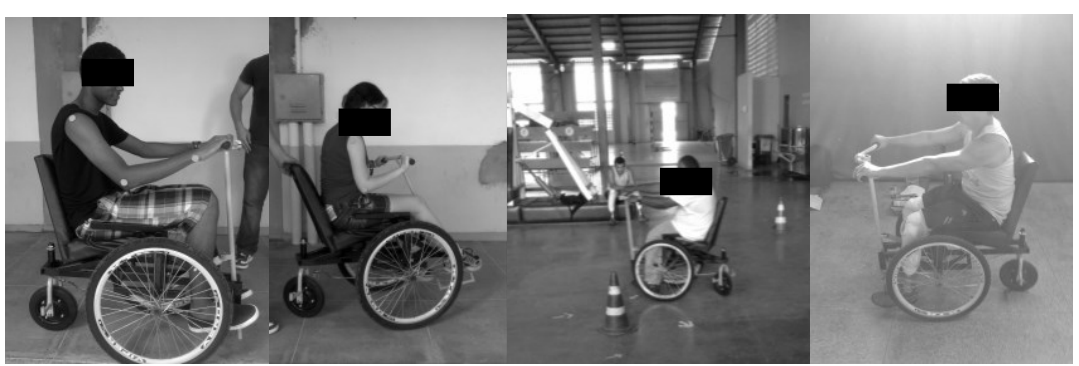

Fonte: elaborado pelos autores.

\subsection{Questionário Fechado (Protocolo de Avaliação)}

De acordo com a figura 7, os resultados apontam níveis de satisfação para os itens: esforço físico necessário para locomoção (72,5\%); material constituinte do revestimento do assento e do encosto $(71,25 \%)$. O componente que obteve menor nível de satisfação foi o apoia-pés, que atingiu $30 \%$ da escala de satisfação. Em uma análise geral pode-se verificar que os sujeitos, após o uso simulado do assento, mostraram-se satisfeitos com a handbike, tendo uma média de $60 \%$ de aprovação de todos os componentes analisados.

Figura 7. Resultado do questionário fechado (protocolo de avaliação)

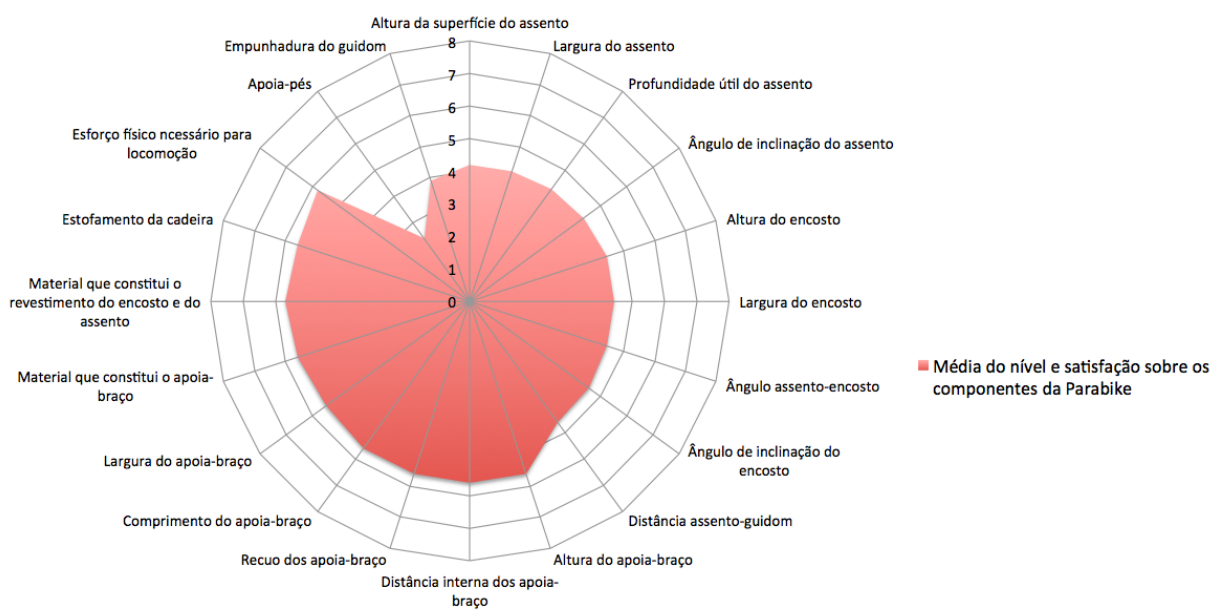

Fonte: elaborado pelos autores 


\subsection{Mapa de Regiões Corporais (MRC)}

Em relação aos membros superiores - lado esquerdo, observa-se que houve nível reduzido de desconforto/dor, tendo o antebraço e o cotovelo como os maiores níveis (média de 0,5 cm), e o punho o menor índice de desconforto/dor $(0,25)$. Analisando os membros superiores - lado direito, observou-se certa similaridade com o lado direito, não havendo nível de desconforto/dor acima de $0,5 \mathrm{~cm}$, ficando o ombro, braço e punho com $0,5 \mathrm{~cm}$ e o cotovelo, antebraço e mão com $0,4 \mathrm{~cm}$. No último segmento, relacionado ao tronco, todos os aspectos analisados obtiveram uma média de $0,2 \mathrm{~cm}$. A avaliação subjetiva geral de desconforto/dor apontou nível reduzido de desconforto/dor durante a utilização da handbike avaliada (figura 8).

Figura 8. Resultado do MRC (adaptado de Corlett, 1995).

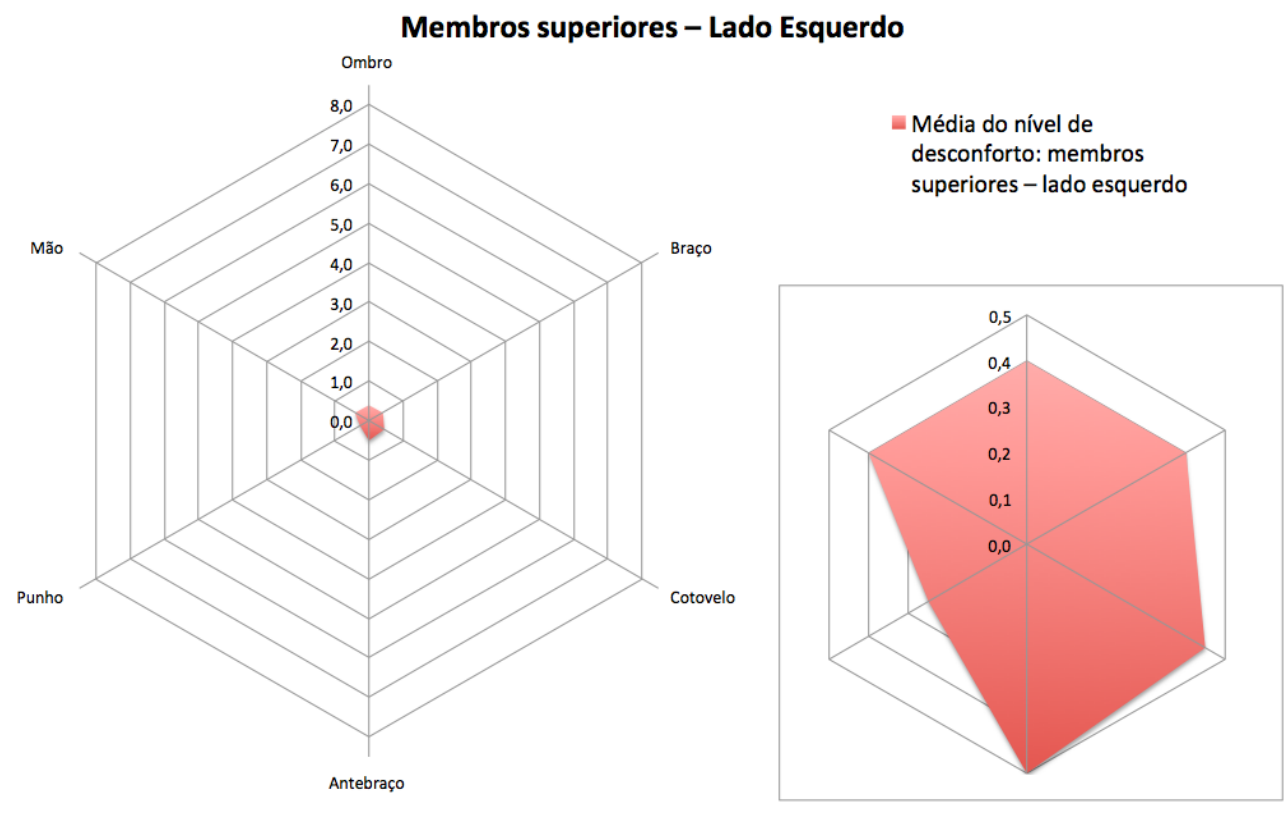

Fonte: elaborada pelos autores.

\subsection{Fatores inerentes às normas e recomendações técnico-científicas}

Quanto à NBR 9050:2004, observou-se que a handbike possui medidas dimensionais discrepantes, assim como os parâmetros dimensionais propostos por PANERO \& ZELNIK (2000), DREYFUSS (2005) e RAMOS (2004), onde é possível verificar que a parabike possui todos os dimensionamentos discrepantes dos propostos pelos autores, com alguma exceções com relação à dimensionamentos ausentes e àqueles que podem apresentar variação de acordo com cada caso de deficiência (figura 9). 
Figura 9. Quadro comparativo dos parâmetros dimensionais $(\mathrm{em} \mathrm{cm})$ entre a handbike e a literatura.

\begin{tabular}{|c|c|c|c|c|c|}
\hline DIMENSOES REFERENCIAIS & PARABIKE & $\begin{array}{l}\text { NBR } \\
9050\end{array}$ & $\begin{array}{c}\text { PANERO\& } \\
\text { ZELNIK (2000) }\end{array}$ & $\begin{array}{l}\text { DREYFUSS } \\
\text { (2005) }\end{array}$ & $\begin{array}{l}\text { RAMOS } \\
(2004)\end{array}$ \\
\hline $\begin{array}{l}\text { Largura total da vista frontal; } \\
\text { Largura total da vista lateral; }\end{array}$ & $\begin{array}{l}51,25 \\
107,25\end{array}$ & $\begin{array}{l}60 \text { a } 70 \\
95 \text { a } \\
115\end{array}$ & $\begin{array}{l}63,5 \\
106,7\end{array}$ & $\begin{array}{c}66,0 \\
106,7 \text { a } 114 \\
3\end{array}$ & $\begin{array}{c}x \\
110,0\end{array}$ \\
\hline Largura do encosto; & $\begin{array}{l}\text { Encosto no formato } \\
\text { trapezoidal de base } 35,00 \mathrm{e} \\
\text { para o topo } 20,25\end{array}$ & 40 a 46 & $x$ & $\mathrm{x}$ & 40,0 \\
\hline $\begin{array}{l}\text { Distância entre o eixo central } \\
\text { do encosto e a borda da roda } \\
\text { traseira. }\end{array}$ & 25,15 & 25 & $x$ & $x$ & $x$ \\
\hline Largura do assento; & 33,50 & 40 a 46 & $\mathrm{x}$ & $\mathrm{x}$ & 43,0 \\
\hline $\begin{array}{l}\text { Distância entre a borda do } \\
\text { assento e o apoio para os } \\
\text { pés; }\end{array}$ & $\begin{array}{c}\text { Não possui apoio para os } \\
\text { pés }\end{array}$ & 30 a 40 & $\mathrm{x}$ & $\mathrm{x}$ & $\mathrm{x}$ \\
\hline $\begin{array}{l}\text { Profundidade do apoio para } \\
\text { os pés; }\end{array}$ & $\begin{array}{c}\text { Não possui apoio para os } \\
\text { pés }\end{array}$ & $\mathrm{x}$ & $\mathrm{x}$ & 15,0 & 24,0 \\
\hline $\begin{array}{l}\text { Profundidade do assento na } \\
\text { vista lateral; }\end{array}$ & 41,50 & 42 a 45 & $\mathrm{x}$ & $\mathrm{x}$ & $37,5-42,5$ \\
\hline Altura do assento até o chão; & 60,15 & 49 a 53 & 49,5 & 48,5 & $\mathrm{x}$ \\
\hline $\begin{array}{l}\text { Altura do apoio para os } \\
\text { braços até o chão; }\end{array}$ & $\begin{array}{l}\text { Não possui apoio para os } \\
\text { braços }\end{array}$ & $\begin{array}{l}71 \text { a } \\
72,5\end{array}$ & 73,7 & $\mathrm{x}$ & $\mathrm{x}$ \\
\hline $\begin{array}{l}\text { Profundidade do apoio para } \\
\text { os braços; }\end{array}$ & $\begin{array}{c}\text { Não possui apoio para os } \\
\text { braços }\end{array}$ & $\mathrm{x}$ & $\mathrm{x}$ & 76,0 & 38,0 \\
\hline $\begin{array}{l}\text { Altura da empunhadura de } \\
\text { auxilio; }\end{array}$ & $\begin{array}{l}\text { Não possui empunhadura } \\
\text { de auxílio }\end{array}$ & 92,5 & 91,4 & 91,5 & 90,0 \\
\hline Largura da roda; & 1,6 & 1,5 & $\mathrm{x}$ & $\mathrm{x}$ & $\mathrm{x}$ \\
\hline Diâmetro da roda traseira; & $x$ & $\mathrm{x}$ & $\mathrm{x}$ & 61,0 & $\mathrm{x}$ \\
\hline Diâmetro da roda dianteira; & $\mathrm{x}$ & $\mathrm{x}$ & $\mathrm{x}$ & 20,3 & $\mathrm{x}$ \\
\hline $\begin{array}{l}\text { Distância entre o eixo central } \\
\text { da roda dianteira e o ângulo } \\
\text { de abertura do apoio para os } \\
\text { pés. }\end{array}$ & $\mathrm{x}$ & $\mathrm{x}$ & $\mathrm{x}$ & 20,5 & $\mathrm{x}$ \\
\hline Comprimento do encosto & 43,05 & $\mathrm{x}$ & $\mathrm{x}$ & $\mathrm{x}$ & $75,0-81,0$ \\
\hline $\begin{array}{l}\text { Comprimento da parte } \\
\text { superior do encosto }\end{array}$ & $\begin{array}{l}\text { Encosto no formato } \\
\text { trapezoidal de base } 35,00 \mathrm{e} \\
\text { para o topo } 20,25\end{array}$ & $\hat{x}$ & $\hat{x}$ & $\hat{x}$ & 45,0 \\
\hline $\begin{array}{l}\text { Comprimento da parte } \\
\text { inferior do encosto }\end{array}$ & $\begin{array}{l}\text { Encosto no formato } \\
\text { trapezoidal de base } 35,00 \mathrm{e} \\
\text { para o topo } 20,25\end{array}$ & $x$ & $x$ & $x$ & $30,0-36,0$ \\
\hline $\begin{array}{l}\text { Altura do apoio para os } \\
\text { braços até o assento }\end{array}$ & $\begin{array}{c}\text { Não possui apoio para os } \\
\text { braços }\end{array}$ & $\mathrm{x}$ & $\mathrm{x}$ & $\mathrm{x}$ & $18,5-23,0$ \\
\hline $\begin{array}{l}\text { Largura do apoio para os } \\
\text { braços }\end{array}$ & $\begin{array}{l}\text { Não possui apoio para os } \\
\text { braços }\end{array}$ & $\mathrm{x}$ & $\mathrm{x}$ & $\mathrm{x}$ & 4,0 \\
\hline $\begin{array}{l}\text { Altura do apoio dos pés } \\
\text { (medida da borda do assento } \\
\text { até o apoio para os pés); }\end{array}$ & $\begin{array}{c}\text { Não possui apoio para os } \\
\text { pés }\end{array}$ & $\mathrm{x}$ & $\mathrm{x}$ & $\mathrm{x}$ & $32,5-45,5$ \\
\hline $\begin{array}{l}\text { Altura do batente do } \\
\text { tornozelo }\end{array}$ & $\begin{array}{l}\text { Não possui apoio para os } \\
\text { braços e consequentemente } \\
\text { não haverá para o tornozelo }\end{array}$ & $\mathrm{x}$ & $\mathrm{x}$ & $\mathrm{x}$ & $\mathrm{x}$ \\
\hline
\end{tabular}

Fonte: elaborado pelos autores

Buscaram-se novas fontes de pesquisa e literatura disponível para além de obter um dimensionamento ideal para a handbike, garantir a segurança e usabilidade da mesma. Como é o caso do aro de propulsão manual, elemento muito comum nas cadeiras de rodas convencionais, que segundo WEI (et.al, 2003 apud ELLUI et.al, 2012), é a fonte primária de mobilidade para muitas pessoas com deficiência. Em contrapartida, DEBROCHES (et.a., 2008 apud ELLUI, et.al.,,2012) afirmam que a propulsão manual de cadeiras de rodas tem sido associada com alta prevalência de dor com um aumento de risco $(31 \%$ a $73 \%)$ de desenvolvimento de lesões nos membros superiores.

Segundo DIERUF (et.al., 2008 apud ELLUI, et.al. 2012), o aro de propulsão é um tubo circular feito de aço inoxidável ou alumínio leve, usado para a autopropulsão manual de cadeira de rodas. Estes aros são padronizados e disponíveis nas cadeiras de rodas, não possuem características ergonômicas uma vez que são muito pequenos para proporcionar preensão nos pontos de contato da mão, aumentando as forças transmitidas a estruturas delicadas da mesma. Afirmam ainda que a inabilidade em agarrar o aro com a palma da mão inteira e os dedos reduz a eficiência mecânica por recrutar musculatura para estabilização da mão no aro ao invés de promover potência à propulsão da cadeira. (RICHTER; NOON; AXELSON, 2007). Então, ELLUI (et.al., 2012) com base nos dados antropométricos da mão, levantados por PASCHOARELLI et al. (2008) que estipula o comprimento da mão pelo valor aproximado de $18,5 \mathrm{~cm}$, consideram adequado ao aro oferecer aproximadamente $12 \mathrm{~cm}$ de contato para a mão, quase o dobro dos insuficientes $6,28 \mathrm{~cm}$ do aro convencional de $2 \mathrm{~cm}$ de diâmetro (figura 9). 


\subsection{Cinemetria (avaliação do esforço físico)}

Constatou-se que o indivíduo sentado segura o guidão (puxador) e aplica força o suficiente para trazê-lo próximo a altura do peito (acima da parte superior do abdômen) realizando flexão do ombro e cotovelo, em seguida, para retornar o guidão a sua posição inicial realiza a extensão do ombro e cotovelo. Desta maneira, por questões metodológicas utilizaram-se conhecimentos advindos da técnica da remada baixa para análise do presente estudo. A pegada utilizada nesse tipo de exercício pode ser de três tipos: a supinada, pronada e neutra. $O$ movimento executado pelos voluntários no teste foi dividido em duas fases: Fase de Flexão do Cotovelo (FFC) e Fase de Extensão do Cotovelo (FEC). A FFC caracteriza-se pela aplicação de força para realizar $01^{\circ}$ deslocamento, nela o individuo deve trazer o guidão até próximo a altura do peito (acima da parte superior do abdômen) realizando flexão do ombro e cotovelo (figura 10).

Figura 10. Resultado da Fase de Flexão do cotovelo.

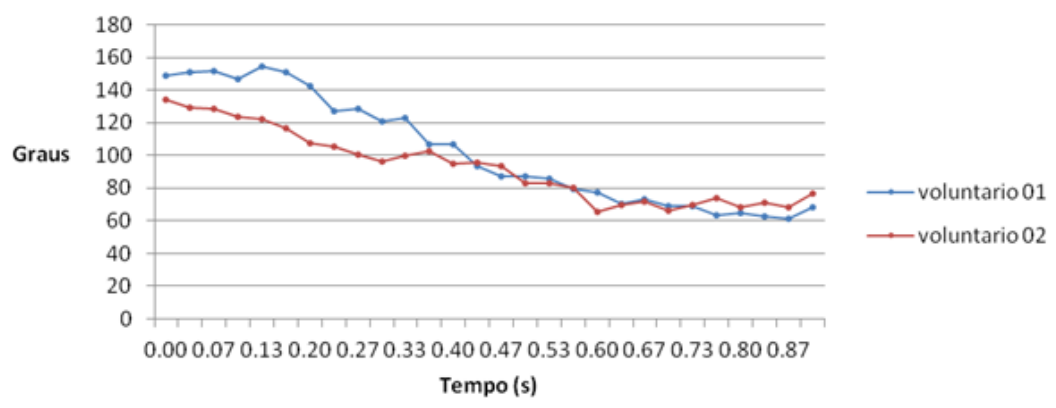

Fonte: Elaborada pelos autores.

Durante o teste, as maiores variações angulares do cotovelo na FFC foram obtidas pelo voluntário 01 , apresentando média de $105,50^{\circ}$ enquanto que o voluntário 02 apresentou $94,37^{\circ}$ respectivamente. A diferença na variação angular possivelmente foi devido a maior estatura e maior comprimento do membro superior do voluntário $01 \mathrm{em}$ relação ao voluntário 02. De acordo com os autores (Hamill \& Knutzen 1999) o pico de torque máximo do cotovelo está entre 80 e $90^{\circ}$, quando o antebraço está na posição supinada, neste momento, o músculo bíceps braquial está levemente estirado o que resulta numa maior produção de força. No entanto, Sacco \& Tanaka (2008) afirmam que não só o bíceps braquial, mas os flexores do cotovelo apresentam uma melhor produção de força próximo dos $90^{\circ}$. Assim, pode-se constatar que o voluntário 02 permaneceu com a angulação do cotovelo mais próximo do pico de produção de força, o que possivelmente pode ter facilitado o seu deslocamento. A Fase de Extensão do Cotovelo caracteriza-se pelo $2^{\circ}$ deslocamento e retorno à posição inicial do guidão, nesta fase as médias angulares obtidas pelos voluntários 01 e 02 foram: 95,33 $\mathrm{e}$ $128,18^{\circ}$ respectivamente. De acordo com Anders (2005) apud LOSS os extensores do ombro apresentaram maior atividade eletromiográfica nos graus de movimento que variam entre $60^{\circ}$ a $90^{\circ}$. Assim é possível constatar que os voluntários 01 e 02 ao realizar o movimento fizeram uso dos extensores do ombro sem utilizar a sua máxima eficiência. Porém o voluntário 02 foi o que mais se distanciou dos valores de pico máximo nesta fase.

\subsection{Freqüência Cardíaca (FC)}

Os resultados da FC mostraram que houve esforço elevado entre os sujeitos, com níveis consideráveis de FC média entre todos, em torno de 100 batimentos por minuto (figura 11). 
Figura 11. Resultados tabulados a partir das médias

\begin{tabular}{|c|c|c|c|c|}
\hline & \multicolumn{2}{|c|}{ Grupo A } & \multicolumn{2}{|c|}{ Grupo B } \\
\hline $\begin{array}{l}\text { Sujeitos } \\
\text { FC } \\
\text { FC Média }\end{array}$ & $\begin{array}{l}\mathrm{P} 95 \mathrm{H} \\
78 \mathrm{bpm} \text { a } 99 \mathrm{bpm} \\
127,5\end{array}$ & $\begin{array}{l}\text { P5M } \\
86 \text { bpm a } 122 \text { bpm } \\
104\end{array}$ & $\begin{array}{l}\text { Sujeito } 1 \\
87 \text { bpm a } 103 \text { bpm } \\
95\end{array}$ & $\begin{array}{l}\text { Sujeito } 2 \\
89 \mathrm{bpm} \text { a } 184 \mathrm{bpm} \\
136,5\end{array}$ \\
\hline Tipo de esforço & $\begin{array}{l}\text { Extremamente } \\
\text { pesado }\end{array}$ & Esforço pesado & $\begin{array}{l}\text { Medianamente } \\
\text { pesado }\end{array}$ & $\begin{array}{l}\text { Extremamente } \\
\text { pesado }\end{array}$ \\
\hline
\end{tabular}

Fonte: elaborado pelos autores

\subsection{Parecer Técnico ergonômico e recomendações de melhoria}

No geral, foram encontrados pontos relevantes que indicam que os problemas a serem estudados de forma mais aprofundada estão relacionados ao handbike. Como problemas de ordem acidentários: cantos vivos e elementos perfuro/cortantes (presentes no apoio de braços, na base dos eixos traseiro e dianteiro); problemas de ordem Espacial/Arquitetural, como o tridente dos eixos, que dificulta a circulação ao redor da handbike; problema de ordem movimentacional, problemas no eixo de direção que pode causar em acidentes devido à postura inclinada e falta de apoio de braços, cinto de segurança e a largura entre os eixos, o usuário fica privado de efetuar tração e realizar a curva; problema de ordem estrutural, como fadiga em peças e problemas de ordem natural, material feito em ferro, propício a ataques químicos que provocam oxidação de tal material.

Além dos fatores dimensionais, destacaram-se também outros aspectos apontados por Batista, (2005) que devem ser contemplados em projetos relacionados à handbikes, como: sistema de freios simples e sistema de marchas (câmbio), podendo ser similar ao das bicicletas convencionais, sistema de amortecimento; podendo ser usado tanto elas pessoas com deficiência (físico-locomotora) quanto por pessoas sem deficiência; revestimento em tecido e espuma no assento e apoios; tubos, parafusos e todos os componentes do chassi em alumínio, reduzindo assim o peso excessivo da handbike; apresentar resistência ao peso dos usuários (pessoas); apresentar resistência à oxidação (ferrugem); apresentar processo de redução da fadiga dos componentes de união (soldas, roscas e parafusos); possuir estabilidade nas curvas; dispor de cinto de segurança aos usuários; possuir sistema retrátil para transporte, manutenção e limpeza; possuir componentes, incluindo o chassi e todos aqueles que tiverem contato direto com os usuários, sem cantos vivos ou perfuro-cortantes. Assim como possuir aro de propulsão fundamentado em conceitos antropométricos e ergonômicos; possuir empunhadura do guidom que possibilite a alternância entre a pegada neutra, a pronada e supinada e possuir empunhadura de auxílio na parte posterior.

\section{CONSIDERAÇÕES FINAIS}

O presente artigo propôs realizar um teste preliminar, envolvendo situação real de uso, por parte de usuários em potencial, considerando pessoas com deficiência e sem deficiência, com experiência e sem experiência. O objetivo foi, principalmente, gerar subsídios (briefing) relativos ao redesign do referido protótipo no intuito de proporcionar um conjunto de reajustes (feedbacks) referenciais para a elaboração de um protótipo mais refinado. Destaca-se o fato de que os testes preliminares apontaram para uma percepção positiva em relação ao seu uso, com níveis de satisfação elevados por parte dos sujeitos participantes, principalmente dos sujeitos com deficiência.

Enfatiza-se o diferencial do projeto em poder proporcionar uma maneira inovadora de mobilidade pela sua flexibilidade de uso, sendo possível a sua aplicação para fins de realização de atividade física, de inclusão social e de lazer, intercalando as suas 
possibilidades de uso com alternância de acordo com as pretensões dos usuários em potencial. Por outro lado, enfatiza-se, também, a preocupação quanto ao seu uso contínuo em relação ao acionamento por meio de membros superiores (braço, antebraço e mãos) quanto ao componente "guidon", pelo fato de que pela adoção da postura de elevação dos membros superiores em tempo prolongado possa resultar em, num primeiro momento, desconforto/dor das articulações envolvidas e, posteriormente, em possíveis lesões acometidas, principalmente, nas articulações dos mesmos, em especial, nos ombros.

Desta forma, acredita-se que a handbike possui um enorme potencial de uso, podendo ser, inclusive, segmentada/segregada quanto ao seu uso e aplicabilidade, contato que se busque a adequação quanto aos princípios ergonômicos. Por outro lado, recomenda-se expresssamente que se agreguem ao projeto as recomendações antropométricas, biomecânicas, de usabilidade e segurança, enfim, ergonômicas, para que o produto possa ser percebido como referência das questões que permeiam a saúde, segurança, efeiciência e, enfim, qualidade de vida, de seus usuários.

\section{Agradecimentos}

Os autores gostariam de agradecer à Francisco Lobo, Marconi da Silva, Rubenio Barros, Caio Oliveira, André Demaison e Lívia Flávia.

\section{REFERÊNCIAS BIBLIOGRÁFICAS}

ABNT (Associação Brasileira de Normas Técnicas). NBR9050 - acessibilidade de pessoas portadoras de deficiência a edificações, espaço mobiliário e equipamentos urbanos. 2004. disponível em: www.mj.gov.br/sedn/ct/corde/dpdh/corde/abnt/nbr905031052004.pdf. acessado em 11/02/2015.

BATISTA, G. M. Handbike para portadores de deficiência físico-locomotora: uma proposta preliminar. 2004. 119 f. Trabalho de Conclusão de Curso. (Graduação em Desenho Industrial) - Universidade Federal do Maranhão.

BINS ELY, V. H. M. et al. Aplicação do desenho universal em espaços abertos: acessibilidade, autonomia e qualidade de vida para o Idoso. In: SOARES, M. M., VILLAROUCO, V. (eds). ABERGO 2002 - XII Congresso Brasileiro de Ergonomia. ABERGO: Recife, 2002.

CORLETT, $N$. The evaluation of posture and its effects. In: wilson, john $r$. Corlett, e. Nigel. Evaluation of human work - a practical ergonomics methodology. Taylor \& francis: londres, 1995. Pp. $663-713$.

CHAPANIS, Alphonse. Ergonomics in product development: a personalized review. Proceedings of IEA 94. IEA, Toronto. 1994. Vol 1. Pp. $52-54$.

CORDE, Resultado da sistematização dos trabalhadores da Câmara Técnica sobre reserva de vagas para portadores de deficiência - subsídios para regulamentação do artigo $5^{\circ} \& 2^{\circ}$ da Lei 8112/90. Brasília, 1996 (p.7-9).

FOGLIATTO, F. S., GUIMARÃES, L. B. Design Macroergonômico: uma proposta metodológica para projeto de produto. In: Guimarães, L. B. (Ed.), Revista Produto \& Produção. PPGEP/UFRGS: Porto Alegre, 1999. Vol. 3, n. 3, pp. 1 - 15.

GUIMARÃES, L. B. de M. Ergonomia de Processo 1. Universidade Federal do Rio Grande do Sul - Programa de Pós-Graduação em Engenharia de Produção, Porto Alegre:1999, 2 ed. 
HEFFIELD, L. T., HOLT, J. H., REEVES, T. J. Exercise graded by heart rate in electrocardiographic testing for angine pectoris. circulation. 1965. 32: $622-629$.

HIGNeTt, S., McATAMneY, L. Rapid Entire Body Assessment (REBA). Applied Ergonomics. Elsevier Science Ltd. No 31, 2000. pp. $201-205$.

INTERNATIONAL ERGONOMICS ASSOCIATION (IEA). The discipline of ergonomics. Texto recuperado da internet no dia 14/10/2003. http://www.iea.cc/ergonomics/. 2000. Instituto Brasileiro de Geografia e Estatística (IBGE). Censo Demográfico: características gerais da população. Rio de Janeiro, Ministério do Planejamento, Orçamento e Gestão, 2000.

Instituto Brasileiro de Geografia e Estatística (IBGE). Censo Demográfico: características gerais da população - resultados preliminares. Rio de Janeiro, Ministério do Planejamento, Orçamento e Gestão, 2010.

KROEMER, K. H. E. Human strength evaluation. In: Karwowski, W., Marrras, W. S. The Occupational Ergonomics handbook. Londres: CRS press, 1999. pp. $525-546$.

MARCONI, M. LAKATOS, E. Técnicas de pesquisa. Metodologia Científica. $3^{a}$ ed. São Paulo: Atlas, 1996.

McATAMNEY, L.; CORLETT, E. N. (1993) RULA: a survey method for the investigation of work-related upper limb disorders. Applied Ergonomics, 24(2), 91-99.

MORAES, Anamaria de. Ergonomia e conflito homem $x$ máquina: carga de trabalho e custos humanos do trabalho; penosidade física, psíquica e cognitiva. In: MORAES, Anamaria de; VELLOSO, Francisco. J. L. Informatização, automação: sistemas, produtos e programas. Anais do $2^{\circ}$ Encontro Carioca de Ergonomia, Rio de Janeiro, Clube de Engenharia - RJ, 1994. Pp. 3-14.

MORAES, A.; MONT'ALVÃO, C. R. (1998) Ergonomia: conceitos e aplicações. Rio de Janeiro: $2 A B$.

MOURA, L. S. de, FERREIRA, M. C., PAINE, P.A. Manual de elaboração de projetos de pesquisa. Rio de janeiro: EdUERJ, 1998, 134p.

PANERO, J.; ZELNIK, M. Dimensionamento humano para espaços interiores. México: G. Gili, 2008.

PHEASANT, Steven. Bodyspace. Anthropometry, ergonomics and the design of work. London: Taylor \& Francis, 1997.

STONE, H., SIDEL, J., OLIVER, S., WOOLSEY, A., SINGLETON, R.. Sensory Evaluation by quantitative descriptive analysis. Food Technology. 28 (1), 1974, pp. 24 -34 .

TILLEY, A. R. As medidas do homem e da mulher/Henry Dreyfuss Associates; tradução Alexandre Salvaterra. Porto Alegre: Bookman, 2005. 104p. 